http://jmscr.igmpublication.org/home/ ISSN (e)-2347-176x ISSN (p) 2455-0450

crossref DOI: https://dx.doi.org/10.18535/jmscr/v7i12.83

Journal Of Medical Science And Clinical Research

\title{
Evaluate Risks and hazards during using medication cart by nursing students in the critical care unit and plan to improve student competence
}

\author{
Authors \\ Abeer Y. Mahdy ${ }^{1}$, Mageda A. S. Arafat ${ }^{2}$, Azhar A. Mohamed Shehata ${ }^{3}$, \\ Somia. A. Nassar ${ }^{4}$
}

${ }^{1}$ Assistant Professor of Medical Surgical Nursing Department, Faculty of Nursing / Njran University, KSA

${ }^{2}$ Assistant Professor of Nursing Administration, Department of Nursing, College of Applied Medical Science in Wadi Alddawasir, Prince Sattam bin Abdulaziz University- Faculty of Nursing-Benha University- Egypt

${ }^{3}$ Lecturer of Community Health Nursing, Faculty of Nursing / Zagazig University, Egypt, Department of

Nursing, College of Applied Medical Science in Wadi Alddawasir, Prince Sattam bin Abdulaziz University,

KSA

${ }^{4}$ Associate Professor of Clinical Pathology, Department of Medical lab, College of Applied Medical Science in Wadi Alddawasir, Prince Sattam bin Abdulaziz University, KSA

\begin{abstract}
Reverse events are common in health care organizations. Medication errors is the most prevalence of reverse events ; rates range widely from $0.2 \%$ to $90.6 \%$ reflecting differences in the type of medication error(in the UK) this (incidence and prevalence of this nursing problem.

The Aim: evaluate risk and hazards during using medication cart by nursing students in the critical care unit and the plan to improve student competence.

Setting: Study was conducted in the faculty of nursing, Njran University.

Sample: All the available nursing students at levels 6 \& 7 (85).

Tool of Data Collection: nursing students' questionnaire sheet: for assessing nursing students' knowledge regarding medication cart; it include two parts:- Part (1): demographic characteristics of nursing students as: age, educational level. Part (2): students' knowledge regarding medication cart to assess knowledge and attitude toward causes of medication hazards and errors. The score of knowledge test expressed as percent from a maximum of 30 points as follow: $\geq 70 \%$ considered satisfactory level of knowledge. $<70 \%$ considered unsatisfactory level of knowledge. Designed plan to improve student competence.

Results: there was highly statistically significant differences in students' knowledge related to medication cart between pre and post implementation of the plan with $p<0.001 \& P<0.05$. The statistically significant relation between mean score of students' total knowledge regarding $M C$ and age in with $P<0.05$. while there was no statistically significant relation between mean score of their total knowledge with level 7 in both pre \& post implementation of the plan with $P>0.05$.

Conclusions: we concluded that there was a highly statistically significant improvement in nursing students competence regarding medication errors.

Recommendations: study recommend regular nursing instructions and evaluation should apply in various clinics. The instructive booklet ought to increase their competences and additional research is needed to explore how to reduce medication errors.

Keywords: Risks, hazards , medication cart, nursing students, critical care unit, competence.
\end{abstract}




\section{Introduction}

Critical care patients are even more susceptible to medication errors. 1 in 13 adult medical and surgical patients admitted to acute care hospitals in Canada in 2000 experienced an reverse event" Medication errors are the one of this reverse event s that affect patient safety and also cause highly cost for healthcare institutions. As regarded by (Anderson \& Townsend, 2010) about 20\% of medication errors on critical care units are life threatening, and over $40 \%$ of these errors require additional life sustaining treatments. Patients in critical care units at a higher risk of medication errors than patients on the other departments due to their friable health status. Errors and risks during medication administration are very common by student nurses, they have vital role in preventing such errors and risks to prevent hazards for patients. This errors may occur at any area of the medication-use system especially critical and emergency area (Aspden, et al, 2017). The role of nurses in medication management include preparation, calculating, administrating and patient safety (Smeulers et al. 2014). Plan of nursing curriculum should provide students an opportunity to powering nursing skills, perform their knowledge in clinical practices and should demonstrate competency in practical area (King Abdeelazez booklet, 2017). It should be decrease their fair and anxiety and increase their competence in critical area. So the undergraduate nursing students should enhance familiar by equipment and all resources used as medication cart by deliberate practice and experimental learning also.

The key role of the nurses is the secure and efficient management of medication (Choo et al., 2010; Simonsen, Daehlin, Johansson, \& Farup, 2014). The thirty four nursing activities, undertaken by professionals, which show complexity and greater possibility of hazards and errors as identified by Volpe, (2017); the weaknesses point identified include human resources, procedure interruptions, displacement, not suitable environment, decrease patient identification, not appropriate infrastructure, pharmacotechnical hazards during preparation and administration, in addition in compliance with nursing protocols rules and security during giving medication. Inappropriate or knowledge deficient about emergency medication leads to medication hazards and errors. Which are difficult to discover. the crises of medication management include some phases including; medication prescribing, transcribing, medication ordering, dispensing, supplying, administering and storing in critical and emergent situation. National Coordinating Council for Medication Error Reporting and Prevention (NCCMERP) (2017) mentioned that measurement of medication hazards and error rates varies between areas ,also observed that rates were higher in critical than the self-reported rates. Decreased rates leads to reduction mortality rate, and decreased hospital stay and suggest improved patient. The complexity of nursing practice in emergency and critical area is environment and crowded area this increase demands of high level of competence of student nurses with little experience.

National Coordinating Council for Medication Error Reporting and Prevention (NCCMERP, 2016) reported that recent studies mentioned factors in relation to medication hazards and errors as hindering during medication medical rounds, medication dosage calculation mistakes (Evans 2009), student nurse knowledge deficit about medication administration and management and bad communication with health team, inability to follow pertinent medication protocols with rule violations and inappropriate student nurse performance and staffing or inadequate resources, job tension and carrying complicated tasks, incompetence staff and lack of professional development ,inadequate system of error information exchange, increased number of highrisked patients, complex technologies (Fry \& Dacey 2007; Jones, 2009; Mahmood et al. 2011; Alshaikh et al. 2013; Smeulers et al. 2014; HEarkEanen et al. 2016 ). 
Nursing education is an important issue that has attracted many health specialists and planners' attention. Development of human society needs, dynamic characteristic of training, and new health and medical policies are among the most important reasons for continuous changes in nursing profession and its related training methods (Ardalan, 2013). Nursing education needs to play its key role in training innovative, committed and responsible students so that, the students can effectively take different roles and critical nursing duties in different situations (Marzouk, 2015). Nursing schools has long utilized simulation in some form to teach principles and skills of nursing care. Simulation in nursing education in the form of static manikins, role playing, CPR manikins, and other techniques has also been utilized as a teaching modality for quite some time. Nursing education programs are faced with increased pressure to produce graduates who are capable of providing safe patient care. Toward that end, nursing education programs develop curricula, use qualified faculty, and select learning experiences for students in an effort to train and graduate competent, effective trainer. The instructional strategies utilized in both theoretical and clinical components of nursing education courses are highly influential in determining critical thinking and clinical decision making ability, as well as in developing the psychomotor skill performance of new graduates (Rivers and Joynelle, 2012). Plan for Learning practical skills especially in fields of emergency and critical nursing is significantly important. Nursing education take effectively different roles and critical nursing duties in different situations as using emergency medication cart one aspect of nursing practice that is bandage skill which requires preparation, good knowledge base, decision skill, and paying attention is medication cart using during the cardio pulmonary resuscitation. Regarding different teaching methods, different students have always put emphasis on this fact that none of the existing methods, media and teaching resources can cover all dimensions and goals of education. In fact, educational models are composed of different teaching methods each of which is utilized to meet different educational goals (Ardalan et al., 2013).

Cardiac arrest occurs in a wide variety of settings, from the unanticipated event in the out-of-hospital setting to anticipate in the intensive care unit. Outcome of cardiac arrest is affected by many factors such as the willingness of by standards to perform CPR, the ability of rescuers to integrate knowledge and psychomotor skills, the quality of performance delivered by individual rescuers and teams, and the efficiency and effectiveness of post- cardiac arrest care (Kitamura et al., 2014).CPR is an emergency procedure using to resuscitate blood circulation and breathing for someone experiencing cardiac arrest. Decisions about CPR are often made in seconds by rescuers (Moore, 2015). The drug therapy for cardiac arrest is toward simplification of the process and treating the patient on a standard protocol. Adrenaline; given intravenously $1 \mathrm{mg}$ of every second cycle of CPR. As CPR is delivered for 2 minutes every cycle, this means that adrenaline is given every four-and-a-bit minutes (compared to every 3 minutes in the previous guidelines). In patients with ventricular fibrillation and pulseless ventricular tachycardia, the first action would be to defibrillate as soon as possible followed by 2 minutes of CPR and the second defibrillation, after which adrenaline should be started and repeated every second cycle. In a pulseless electrical activity arrest or a systolic arrest the adrenaline should be started as soon as possible and again repeated every second cycle. The dose of adrenaline should be given with a significant fluid push (100 mL) behind it (Boyd and Brady, 2012). Nursing students to have a high standard of knowledge and skills. Nursing educators are challenged to teach students to think critically and application of knowledge as assessing, planning, implementation, and evaluation nursing care (Brannan, White and Bezanson, 2014).

Communication is an integral component of nursing education and has been shown to improve 
CPR outcomes, patient compliance, and patient satisfaction. Nursing students need to be skilled at patient communication to provide a supportive work environment, protect the patient, and convey essential information. (Doolen et al., 2014). Higher levels of self-confidence related to various aspects of patient care, including clinical decision making, and physical assessment. Nursing students believe they learn more and feel more confident with mastery of skills and knowledge when using lab simulations and indicated confident in developing skills and knowledge to perform in the clinical setting (Foster, Sheriff and Cheney, 2008).

Perceived self-efficacy is among the factors that affect human motivation and refers to the belief in one's own capabilities to perform given actions. Persons with high self efficacy are more likely to make more effort in a specific task, sustain that effort and resist adversity longer than those with low self-efficacy. Self-efficacy student should become familiar with patient care. Clinical reasoning is an essential component of competent nursing practice; it is a process that involves both cognition and metacognition (or reflective thinking) and is dependent on a critical thinking (disposition). Development of clinical reasoning skills enhances the nursing students' ability to build on previously acquired knowledge and past experience in order to address new or unfamiliar situations. Nursing students with effective clinical reasoning skills have a positive impact on patient outcomes (Lupien and George-Gay, 2010).

For the prevention and management of medication errors, the examination of the basic nursing curricula at undergraduate levels for coverage of competencies is necessary. To develop competences in characteristics necessary in nursing professional practice as improve skills, knowledge which classified into behavioral and technical. Both of them based on student knowledge and may need to professional judgment and student able to clinical decision making. On one side, technical competencies contain admonition and managing administration of medication as well as dosage calculation. On the other hand, competencies in student behavior it contain articulation of nursing scope of practice to others, practicing ethical code for registered nurses, use evidences and critical inquiry to challenge, to support nursing practical issue. These competencies in collaboration with other health care team to rapid changing emergent situation and preserve health. To reducing the risk of errors. Organizations as trainer should prospectively design and implement efficient strategies to reduce hazards and errors to prevent patient harm. Areas that must be addressed are high-risk populations as emergency and critical , high-risk, should high-alert for medications, and easily confused drug names, also known as "lookalike/sound-alike" (LASA) medications. Plane for Risk-reduction strategies should be implemented to prevent errors, make errors visible, and mitigate the harm if an error occurs.

\section{Significant of the study}

The nurses today must be avoid risks and hazards and must be competent in critical area . so that should improve learners' skills in a safe, nonthreatening experimental environment. Researchers observe a lot of medication cart hazards and errors, So that, they decide focus on this problem

\section{Aim of the study}

The aim of the study was to evaluate risks and hazards made by nursing students during using medication cart in the critical care unit and plan to improve student competence.

\section{Research Hypothesis}

1. The mean score student knowledge about risks and hazards during using medication cart in the critical care unit will be increase after implementing the plan to improve student competence.

2. The mean score of nursing students' level knowledge regarding indication of medication cart as arrest, CPR, in the study 
group will be higher after implementing the plan to improve student competence.

\section{Subjects and Methods}

\section{Research Design}

Quiz- experimental design utilized to conduct the aim of the study.

\section{Setting}

This study was conducted at Faculty of Nursing Njran University.

\section{Subjects}

All available nursing students in academic year (2015-2017) were recruited in this study

Tool of data collection: Nursing students' questionnaire sheet: it was constructed by the researcher after reviewing relevant literature. It was written for assessing nursing students' knowledge regarding medication cart include two parts: Part (1): Demographic characteristics of nursing students as: name, age, gender group, educational level, learning experiences and number of training program. Part (2): (A) students' knowledge regarding medication cart: it was include signs and symptoms to use medication cart, first aid for arrest, principles, indication, main components for priority of using medication cart as CPR, medication cart content .(B): Students' knowledge regarding medication cart (MC): it was include meaning of $\mathrm{MC}$, describe of $\mathrm{MC}$, indications, maintenance and store, requirement, arrangement wheel.

\section{Knowledge scoring system}

All knowledge variables were weighted according to the items included in the model answer of each question. The data collected from the knowledge test was computed and the test received a grade out of questions for cases priority and questions for $\mathrm{MC}$, the scores were allocated as follows: right (1) and wrong (0). The score of knowledge test expressed as percent from a maximum of 30 points as follow:

$\geq 70 \%$ considered satisfactory level of knowledge.

$<70 \%$ considered unsatisfactory level of knowledge. reviewing the available literature and different studies related to research problem, and theoretical knowledge of its various aspects of the study, using textbooks, evidence-based articles, internet periodicals and magazines in order to collect tools of this study. This period extended from (February 2014 to June 2014).

\section{Designing plan to improve competence}

Based on literature review, the researcher designed plan to improve student competence it was developed and constructed by the researcher in the form of booklet. The booklet consisted of theoretical orientation and explanation the knowledge related to medication cart and arrest signs \& symptoms. purposes, indication, principles, causes, phases, complications, advanced techniques for airway management and drugs used in CPR. An explanation about MC such as (description, indication, arrangement , equipment, precautions). Knowledge related to record.

\section{2- Tool validity and reliability}

Validity: aimed at testing the validity of the proposed tools by using face and content validity. Face validity aimed at inspecting the items to determine whether the tools measure what supposed to measure. Content validity was conducted to determine whether the tools cover the aim. Testing validity was tested though a jury of 5 experts.

The Testing reliability of proposed tools was done by Cronbach alpha test.

\section{3-A Pilot study}

Pilot study was carried out on $10 \%$ (9) students of the studied subjects, who were included in the main study. The pilot study was done to ensure clarity, applicability, feasibility of conduction of the study tools, and time needed for each tool to be filled in some modifications were done according to the pilot study findings. Some questions and items were omitted, added or rephrased, and then the final forms were developed experts reviewed the tools for clarity, relevance, comprehensiveness and simplicity \& applicability. This phase take one month. 


\section{4-Ethical consideration}

The ethical considerations of this study included the following:

The researcher clarified the purpose, requirements, duration and anticipated benefits of the study to the nursing students. Approval was granted for this study, assured maintaining anonymity and confidentiality of the subjects' data., informed student that they are allowed to choose to participate or not in the study and they had right to withdraw from the study at any time, tools were not causing any harm or pain for the nursing students.

\section{5-Field work}

The researchers reviewed current related literature and theoretical knowledge of the various aspects that concerning topic of the study to develop and construct the study tools of data collection. And planning for improvement of student competency. Translating tool into Arabic language to clear understand. The researchers started to assess the readiness of the subjects in the study setting to announce and encourage participation in the study. Approval to carry out this study was granted from the coordinator of medical surgical nursing department. The researcher was distribute questionnaire interview for students after explain the objectives and the nature of the study to obtain base line data about student knowledge and then carry out the plan to improve student knowledge and competence during using medication cart with minimum resistance. The process of data collection. Theoretical part conducted students' in class room and took 2 hours. The researcher was started the evaluation phase after finishing at the next week.

\section{Statistical Design}

The collected data were organized, coded, computerized, tabulated and analyzed by using the statistical package for social science (SPSS), version (23). Data analysis was accomplished by the use of number, percentage distribution, mean, standard deviation, and correlation, coefficient, Paired t-test and multiple linear regression analyses was used to test the significance of some variances. A significant level value was considered when $\mathrm{p}<0.05$.

\section{Results}

Table (1) \& Figure (1): demonstrated distribution of demographic characteristics among studied nursing college students, and showed that the majority of the studied group $(76.5 \%)$ with mean age $(20.0235+.687)$ and more than two thirds $(71.8 \%)$ derived from level 6 . In relation to distribution of knowledge related to cardiac arrest \& CPR among the studied students, Table (2) demonstrated that; there was highly statistical significant difference of knowledge related to medication cart, risks and hazards among the studied college nursing students with $(\mathrm{p}<0.001 \&$ $\mathrm{P}<0.05$ ), while some items as; maintenance and store error, an expired and restocks or replaces emergency equipment and medications mentioned no statistically significant differences $(\mathrm{P}>0.05)$.

Table (3): revealed to the mean score of studied college nursing students' total knowledge related to medication cart among studied college nursing students during pre and post implement of the plan, it showed highly statistically significant differences in students' knowledge related to medication cart between pre and post with ( $\mathrm{p}$ $<0.001 \& \mathrm{P}<0.05$ ), while in items related to maintenance and store, stability and wheel there was no statistically significant differences (P > 0.05). Table (4): revealed to the mean score of studied students' total knowledge regarding risks and hazards ,arrest, and medication cart pre and post implement plan, the results revealed to highly statistically significant differences $(\mathrm{P}<0.001)$. Table (5): This table illustrated the statistically significant relation between mean score of students' total knowledge regarding $\mathrm{MC}$ and age in with $\mathrm{P}<0.05$.while there was no statistically significant relation between mean score of their total knowledge with level 7 in both pre \& post implementation of the plan with $\mathrm{P}>0.05$. 
Table (1): Distribution of demographic characteristics among the studied nursing college students

\begin{tabular}{|c|c|c|c|c|}
\hline \multirow[t]{2}{*}{ Demographic characteristics } & \multicolumn{2}{|c|}{$\begin{array}{c}\text { Study subjects } \\
(n=85)\end{array}$} & \multirow[t]{2}{*}{ Chi-square $\chi^{2}$} & \multirow[t]{2}{*}{$\begin{array}{c}\mathbf{P} \\
\text { Value }\end{array}$} \\
\hline & No & $\%$ & & \\
\hline \multicolumn{3}{|l|}{ Age in years } & \multirow{4}{*}{3.71} & \multirow{4}{*}{$>0.05$} \\
\hline $19-20$ yrs. & 65 & 76.5 & & \\
\hline $20-23$ yrs. & 20 & 23.5 & & \\
\hline Mean \pm SD & \multicolumn{2}{|c|}{$20.0235+.687$} & & \\
\hline \multicolumn{3}{|l|}{ Educational level } & \multirow{3}{*}{1.65} & \multirow{3}{*}{$>0.05$} \\
\hline Level 6 & 61 & 71.8 & & \\
\hline Level 7 & 24 & 28.2 & & \\
\hline
\end{tabular}

no statistically significant at $>0.05$

Distribution of demographic characteristics among studied college nurses $(\mathbf{n}=85)$

Level 7

$14 \% \quad 0 \%$

Age in years
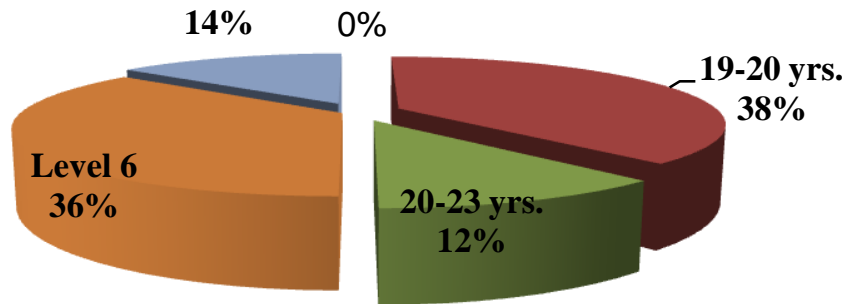

Level 6

$0 \%$

Level 7

Figure (1): Distribution of demographic characteristics among the studied nursing college students

Table (2): Distribution of knowledge related to medication cart, risks and hazards among the studied college nursing students

\begin{tabular}{|c|c|c|c|c|c|}
\hline \multirow[t]{3}{*}{ Items } & \multicolumn{4}{|c|}{ Study subjects $(n=85)$} & \multirow{3}{*}{$\begin{array}{c}\text { P- } \\
\text { Value }\end{array}$} \\
\hline & \multicolumn{2}{|c|}{ Pre } & \multicolumn{2}{|c|}{ Post } & \\
\hline & No & $\%$ & No & $\%$ & \\
\hline Medication cart risks & 28 & 16.5 & 71 & 83.5 & $<0.001 * *$ \\
\hline Drugs dose error & 0 & 0.00 & 85 & 100.0 & $<0.001 * *$ \\
\hline Maintenance and store error & 9 & 10.6 & 76 & 89.4 & $>0.05$ \\
\hline Arrange drugs in the medication drawer (or clearly labeled & 0 & 0.00 & 85 & 100. & $<0.05^{*}$ \\
\hline In expired & 10 & 11.8 & 75 & 88.2 & $>0.05$ \\
\hline Restocks or replaces emergency equipment and medications & 9 & 10.6 & 76 & 89.4 & $>0.05$ \\
\hline Medical situation need to give Atropine & 17 & 20.0 & 68 & 80.0 & $<0.001 * *$ \\
\hline Action of Amiodarone & 6 & 7.1 & 79 & 92.9 & $<0.001 * *$ \\
\hline The most common drugs in medication cart & 42 & 49.4 & 43 & 50.6 & $<0.05^{*}$ \\
\hline
\end{tabular}

No statistically significant at $>0.05$ Statistically significant at $<0.05^{*}$

Highly statistically significant at $<0.001 * *$ 
Table (3): Distribution of knowledge related to medication cart among studied college nursing students during pre and post implement of the plan

\begin{tabular}{|c|c|c|c|c|c|c|}
\hline \multirow[t]{3}{*}{ Items } & \multicolumn{4}{|c|}{ Studied subjects $(n=85)$} & \multirow{3}{*}{$\begin{array}{l}\text { Chi-square } \\
\chi^{2}\end{array}$} & \multirow{3}{*}{ P- Value } \\
\hline & \multicolumn{2}{|c|}{ Pre } & \multicolumn{2}{|c|}{ Post } & & \\
\hline & No & $\%$ & No & $\%$ & & \\
\hline Definition of medication cart & 8 & 9.4 & 77 & 90.6 & 11.49 & $<0.001 * *$ \\
\hline Describe of medication cart & 40 & 47.1 & 45 & 52.9 & 3.09 & $<0.05 *$ \\
\hline Content of medication cart. & 50 & 58.8 & 35 & 41.2 & 42.02 & $<0.001 * *$ \\
\hline Arrangement of medication cart & 20 & 23.5 & 65 & 76.5 & 5.05 & $<0.05^{*}$ \\
\hline Indication to use & 55 & 64.7 & 30 & 35.3 & 130.88 & $<0.001 * *$ \\
\hline Maintenance and store & 19 & 22.4 & 66 & 77.6 & .648 & $>0.05$ \\
\hline Stability and wheel & 27 & 31.8 & 58 & 68.2 & .682 & $>0.05$ \\
\hline $\begin{array}{l}\text { Hazard symbols and } \\
\text { identification }\end{array}$ & 16 & 18.8 & 69 & 81.2 & 13.14 & $<0.001 * *$ \\
\hline Check and Record & 18 & 21.2 & 67 & 78.8 & 7.13 & $<0.05^{*}$ \\
\hline
\end{tabular}

No Statistically significant at $>0.05$ statistically significant at $<0.05 *$ Highly statistically significant at $<0.001 * *$

Table (4): The mean score of college nursing students' total knowledge regarding risks and hazards, arrest, and medication cart pre and post implement plan

\begin{tabular}{|c|c|c|c|c|c|c|c|c|}
\hline \multirow[t]{2}{*}{ Knowledge } & \multicolumn{3}{|c|}{$\begin{array}{l}\text { Pre implementation of the } \\
\text { plan }(n=85)\end{array}$} & \multicolumn{3}{|c|}{$\begin{array}{l}\text { Post implementation of the } \\
\text { plan }(n=85)\end{array}$} & \multirow{2}{*}{$\begin{array}{l}\text { Independent } \\
\text { t - test }\end{array}$} & \multirow[t]{2}{*}{$P$ value } \\
\hline & Mean & \pm & SD & Mean & \pm & SD & & \\
\hline $\begin{array}{l}\text { Knowledge related to risks } \\
\text { and hazards. }\end{array}$ & 2.4471 & \pm & .73791 & 2.7294 & \pm & .56292 & -3.967 & $<0.0001 * *$ \\
\hline Knowledge related to arrest. & 9.9765 & \pm & 2.39069 & 11.6235 & \pm & 1.63885 & -7.409 & $<0.0001^{* *}$ \\
\hline Knowledge related to MC & 6.0176 & \pm & 1.86679 & 7.5412 & \pm & 1.32391 & -8.680 & $<0.0001 * *$ \\
\hline Total knowledge. & 18.4412 & \pm & 4.04700 & 21.8941 & \pm & 2.43507 & -9.532 & $<0.0001 * *$ \\
\hline
\end{tabular}

Table (5): Relation between college nursing students' total knowledge means score regarding MC Pre and post and demographic characteristics

\begin{tabular}{|c|c|c|c|c|c|c|c|}
\hline \multirow{2}{*}{$\begin{array}{l}\text { Demographic } \\
\text { characteristics } \\
\text { Total } \\
\text { knowledge }\end{array}$} & \multicolumn{3}{|c|}{$\begin{array}{l}\text { Pre implementation of the } \\
\text { plan }(n=85)\end{array}$} & \multicolumn{2}{|c|}{$\begin{array}{l}\text { Post implementation of the } \\
\text { plan }(n=85)\end{array}$} & \multirow{2}{*}{$\begin{array}{l}\text { Independent } \\
\text { t } 1 \text { test } \\
\text { t } 2 \text { test }\end{array}$} & \multirow{2}{*}{$\begin{array}{l}\text { P1 value } \\
\text { P2 value }\end{array}$} \\
\hline & Mean & \pm & SD & Mean & \pm SD & & \\
\hline \multicolumn{8}{|l|}{ Age in years } \\
\hline $19-20$ yrs. & 19.1140 & + & 3.46093 & 22.1154 & +2.39714 & \multirow{2}{*}{$\begin{array}{l}2.85 \\
2.85\end{array}$} & $<0.05^{*}$ \\
\hline $20-22$ yrs. & 17.0714 & + & 4.78200 & 21.1750 & +2.44831 & & $<0.05 *$ \\
\hline \multicolumn{8}{|l|}{ Educational level } \\
\hline Level 6 & 19.0270 & + & 3.70861 & 21.9426 & +2.62631 & \multirow{2}{*}{$\begin{array}{l}2.49 \\
.476\end{array}$} & \multirow{2}{*}{$\begin{array}{l}<0.05^{*} \\
>0.05\end{array}$} \\
\hline Level 7 & 17.3390 & + & 4.44355 & 21.7708 & +1.88205 & & \\
\hline
\end{tabular}

No statistically significant at $>0.05 \quad$ Statistically significant at $<0.05^{*}$

t 1 \& P1 for Pre implementation of the plan $\quad$ t $2 \&$ P2 for Post implementation of the plan

\section{Discussion}

Regarding age, the study results indicated that the majority of students ranged between (19-20) years with mean age of $20.0235+.687$ years, whereas a minority of them was found in age between (2123) years old. This result may be explained by the fact that all the students admitted to any faculty at this age. This findings supported by Salah, (2013) who studied the effect of using simulation based learning versus traditional learning on nursing students' clinical performance of respiratory system and found that the majority of the study and control groups was with age ranged between (19-20) years. Also the present findings in accordance with Marie, (2011) who studied the 
effect of simulation on knowledge, self confidence, and skill performance showed that more than half of the studied sample $\mathbf{5 5 \%}$ was less than 21 years of age. This result disagreement with Al Hadid and Hassan, (2012) in their study about effect of boost simulated session on CPR competency among nursing students and reported that the age of the participants ranged between 21 and 26 year-old, $65 \%$ of them were 21 year-old. Also, disagreement with $\mathbf{M a}$, (2013) who was studying students' perception of satisfaction and self-confidence after a simulation mock code experience and found that most of the participants' (94\%) were with an average age 21.5 years.

Regarding the nursing students' knowledge related to indication of MC as arrest, hazards, the present study revealed that mean score of the nursing students' knowledge related to arrest and hazards in the study group higher after the implementation of the plan. This might be due to researcher able to gasping the knowledge for nursing students and student interest by this items especially level 6 because they study critical curriculum. This result agreed with Salah, (2013) concluded that the using of high fidelity simulation plays an important role to improve nursing students' knowledge and skills. Also Swamy et al., (2013) in a study about role of Sim Man in teaching clinical skills as CPR demonstrated that there was a significant improvement in the students' knowledge and competence to perform CPR. While disagreement with Rezae et al., (2013) in their study about Comparing two training methods for CPR skill stated that there is no statistically significant difference between the mean scores of the total questions regarding knowledge assessment for both groups before and after training.

The findings of the present study showed that mean score of nursing students' knowledge related MC in the studied group higher after implementation of the plan, it showed there was highly statistical significant difference of knowledge related to medication cart, risks and hazards among the studied college nursing students with $(\mathrm{p}<0.001 \& \mathrm{P}<0.05)$, while some items as; maintenance and store error, an expired and restocks or replaces emergency equipment and medications mentioned no statistically significant differences $(\mathrm{P}>0.05)$. this may be activity and simulation during teaching by researcher.Also this result is going in the line of Mohammed, (2014), who reported that there was significant improvement in knowledge after implementation of the educational program. Moreover, this consistent Kirwa and Gakere, (2016), who reported that the continuous practice of hand skills lead to improvement of knowledge and performance. Similarly, Abdeen and Metwally, (2014), who confirmed in their study on fourth year nursing students that there was significant improvement in students' knowledge throughout immediate post and follow up phases of the program. In addition to Creesh et al., (2017), who reported that was statistically significant improvement in the overall test score and each subscale scores including the cognitive subscale examining knowledge which indicates that students' competence increased between the pre-test and post-test period. This finding was consisted with Waxman and Telles, (2010) in their study about the use of Benner's framework in HFS faculty development the bay area simulation collaborative model stated that there was a significant difference in favor of the participants in Sim Man group on both the acquisition and retention of knowledge and skills over time. From the researchers point of view that this improvement might be related to student interest to enhancing and restoring knowledge. This finding is supported by Shoemaker et al., (2015) found that the nursing students' knowledge and critical thinking improved after the simulation teaching and showed the effectiveness of simulation as a teaching strategy to address nursing knowledge and critical thinking skills.

In relation to the nursing students' knowledge and their age, the finding of the current study revealed that there was statistically significant relation, this 
might be due to the nursing students with advanced age have ability to acquire and restore the knowledge. This result is in congruent with Aly, (2010) about impact of a basic life support training program on nurses' knowledge and performance at emergency room and reported that there was significant correlation between age and total basic life support knowledge scores. While this result disagreed with the study conducted by Parajulee and Selvaraj, (2011) about knowledge of nurses towards CPR in a tertiary care teaching hospital in Nepal and reported that there was no significant association between the total knowledge score and age of the study group. As regard as in relation to nursing students' knowledge and their educational level, the finding of the current study mentioned that there was statistically significant relation with level 6 students this might be due to the nursing students from level six have good knowledge about arrest and CPR in their curriculum that may help them to catch knowledge relevant to this issue more than the students from level seven .This finding was supported by the study conducted by Elazazay, (2012) about effect of CPR training program on nurses' knowledge and practice and showed that there was relation between knowledge and nursing students' sociodemographic characteristics for control and study groups and explained that training program was effective in improving nurses' knowledge and practice related to CPR. This result disagreed with Lin and Cheng, (2015) about the role of simulation in teaching pediatric resuscitation and reported that there were no statistically significant differences between age and educational level and baseline knowledge scores between groups. These findings matched with El-Maghraby, (2016), who reported that there was an increase in the total mean scores of newly graduated nurses' knowledge immediately post and after three months post program relative to pre-program. In the same line Hus et al., (2014), who found that the mean score of knowledge was high at post-test than at pre-test. This agree with, Bano, (2017), who stated that sixty two percent of nurses agreed that they feel more confident in their knowledge and skills to provide all aspects of patient-centered rehab nursing care after the class.

\section{Conclusion}

In the light of the study findings, it might be concluded the following:

There was a highly statistically significant improvement nursing students' competence regarding medication errors.

\section{Recommendations}

Based on results of the present study the following recommendations can be suggested:

- Nursing educators should be generalizing using new a teaching strategy in the nursing students' clinical training versus traditional to enhance students' learning outcomes and achieve a higher performance level, competency and critical thinking namely for all a critical skills.

- Training program for undergraduate student nurses address prevention of medication errors.

- Nursing education can play important role in improving medication management through strengthening the basic nursing curricula. Educators can also provide leadership in the improvement of conditions that pose a risk for medication errors in the clinical settings as well as in researching medication errors. The review has a potential to stimulate discourse, research and new practices toward the prevention of medication errors including strengthening the curriculum.

\section{References}

1. Abdeen M.E., and Metwally F., (2014): Effect of decision making training program on critical thinking dispositions among fourth year students. Faculty of Nursing, Zagazig University, Egypt. Pp: 124. 
2. Al Hadid, L. and Hassan, K.S. (2012): Effect of boost simulated session on CPR competency among nursing students: A Pilot Study. Journal of Education and Practice, 3(16):186-189.

3. Alshaikh et al. Mayet A \& Aljadhey $\boldsymbol{H}$ (2013) Medication error reporting in a university teaching hospital in Saudi Arabia. Journal of Patient Safety 9, 145149.

4. Aly, A. (2010): Impact of a basic life support training program on nurses' knowledge and performance at emergency room. Doctorate thesis, Faculty of nursing, Suez Canal University: 56.

5. Anderson, P., \& Townsend, T. (2010). Medication Error: Don't let them happen to you.

From

http://www.americannursetoday.com/asset s/0/434/436/440/6276/6334/6350/

6356/8b8dac76-6061-4521-8b43-

d0928ef8de07.pdf.

6. Ardalan, M., Saleh, M.V. and Salehnejad,G. (2013): Comparing the effects of traditional and combined teaching methods on nursing students' learning skills of wound care. Life Sci J, 10(9s):156-159. Available at: http://www.lifesciencesite.com. Accessed at 22/9/2014.

7. Aspden P, Wolcott J, Bootman JL et al.(2017) : Preventing medication errors: quality chasm series.

www.nap. edu/read/11623/chapter/1 (accessed 2017 Jun 13).

8. Bano S.P., (2017): Mentor-based orientation program. Availableat: https://repository.usfca.edu/cgi/viewconten t.cgi article $=1687 \&$ context $=$ capstone. $\mathrm{P}: 16$.

9. Boyd, T., and Brady, W. (2012): The code drugs in cardiac arrest; the use of cardioactive medications in cardiac
10. arrest resuscitation. Am J Emerg Med; 30(5):811-8. doi: 10.1016/j.ajem.2011.04.009 .

11. Brannan, J.D., White, A. and Bezanson, J.L. (2014): Simulator effects on cognitive skills and confidence levels. Journal of Nursing Education, 47(11): 495-500.

12. Care coordination. Agency for Healthcare Research and Quality. https://www.ahrq.gov/professionals/pre vention-chroniccare/improve/coordination/index.

13. Choo J. Hutchinson A. Bucknall T. (2010). Nurses' role in medication safety. Journal of Nursing Management, 18, 853 861. 10.1111/j.1365-2834.2010.01164.x

14. Creech C., Filter M., Wehbe H., and Mcfarland M., (2017): An intervention to improve cultural competence in graduate nursing education. Nursing Education Prespectives, 38(6), Pp: 334. Available at, file:///C:/Users/hp/Downloads/An_Interve ntion_to_Improve_Cultural_Competence_i n.9.pdf. Accessed on June, 20, 2018.

15. Doolen, J., Giddings, M., Johnson, M., Guizado, G. and Lysander, O. (2014): An evaluation of mental health simulation with standardized patients. International Journal of Nursing Education Scholarship, 11(1): 1-8.

16. Elazazay, H. M., Abdelazez, A. L. and Elsaie, O.A. (2012): Effect of cardiopulmonary resuscitation training program on nurses' knowledge and practice. Life Sci J, 9(4): 3494-3503.

17. El-Maghraby Z.A., (2016): Effect of orientation Program on Competency of Newly Graduated Nurses at Mansoura New General Hospital. Thesis submitted for partial fulfillment of the Doctoral thesis in Nursing Administration, Faculty of Nursing, Zagazig University, Egypt: Pp: 79-125.

18. Evans J (2009) Prevalence, risk factors, consequences and strategies for reducing 
medication errors in Australian hospitals: a literature review. Contemporary Nurse: A Journal for the Australian Nursing Profession 31, 176-189.

19. Foster, J.G., Sheriff, S. and Cheney, S. (2008): Using non faculty registered nurses to facilitate high-fidelity human patient simulation activities. Nurse Educator, 33(3): 137-141.

20. Fry MM \& Dacey C (2007) Factors contributing to incidents in medicine administration. Part 2. British Journal of Nursing (BJN) 16, 676-681.

21. HEark€anen M, Turunen $H$ \& VehvilEainen- Julkunen $K$ (2016) Differences between methods of detecting medication errors: a secondary analysis of medication administration errors using incident reports, the Global Trigger Tool method and observations. Journal of Patient Safety. Published ahead of print 24.3.2016.

22. Hsu L.L., Huang Y., and Hsieh S., (2014): The Effect of Scenario- based Communication training on Nurses, communication Competence and selfEfficacy and Myocardial Infraction Knowledge. Patient Education and Counseling, 95(1), Pp: 356-364. html. Reviewed July 2016. Accessed October 2, 2017.

23. King Abdeelazez booklet, (2017). Kingdom of Saudi Arabia ministry of Higher Education University.

24. Kirwa L., and Gakere Z., (2016): Clinical Competence of Nursing Students. Pp: 27. Available at:https://www. theseus.fi/bitstream/handle/10024/109754/ Kirwa_Lilian. pdf?sequence $=3$. Accessed on July 2018.

25. Kitamura, T., Iwami, T., Kawamura, T., Nagao, K., Tanaka, H., Nadkarni, VM., Berg, R.A., Hiraide, A. (2014): Conventional and chest-compression-only cardiopulmonary resuscitation by bystanders for children who have out-of hospital cardiac arrests: a prospective, nationwide, population-based cohort study. Lancet, 375: 1347-1354.

26. Lin, Y. and Cheng, $A$ (2015): The role of simulation in teaching pediatric resuscitation: current perspectives. Adv Med Educ Pract, 6: 239-248.

27. Lupien, A.E. and George-Gay, B. (2010): Fuszard's innovative teaching strategies in nursing. Lowenstein AJ, Bradshaw MJ, editor. Gaithersburg: Aspen Publishers; High-fidelity Patient Simulation: 378.

28. Ma, X. (2013): Students' perception of satisfaction and self-confidences after a simulation experience: A descriptive study. B.S.N. Cedarville University: 23.

29. Mahmood, A., Chaudhury, H. \& Valente, M. (2011) Nurses' perceptions of how physical environment affects medication errors in acute care settings. Applied Nursing Research, 24 (4), 229-237.

30. Mahmood, A., Chaudhury, H. \& Valente, M. (2011). Nurses ${ }^{\text {ee }}$ perceptions of how physical environment affects medication errors in acute care settings. Applied Nursing Research, 24 (4), 229-237.

31. Marie, A.B. (2011): The effect of simulation on knowledge, self-confidence, and skill performance. Submitted in partial fulfillment of the requirements for the degree of Doctor of Philosophy. Frances Payne Bolton School of Nursing case Western Reserve University: 59.

32. Marzouk, T (2015): Effectiveness of simulated delivery room classes on practical achievement and satisfaction of maternity nursing students. Journal of Nursing Education and Practice, 5 (8): 5159.

33. Moore, K. (2015): CPR for adults. Health line Networks, Inc, pp.1- 4 Available @ http://www. healthline.com/ health/cpradult. Accessed at 2/11/2015. 
34. National Coordinating Council for Medication Error Reporting and Prevention (2017). About medication errors. http://www.nccmerp.org/aboutmedicationerrors. Accessed October 2, 2017.

35. NCCMERP (2016) The National Coordinating Council for Medication Error Reporting and Prevention About medication errors. Available at: http:// www.nccmerp.org/aboutMedErrors.html (accessed 11 April 2016).

36. Parajulee, S. and Selvaraj, V. (2011): Knowledge of nurses towards cardiopulmonary resuscitation in a tertiary care teaching hospital in Nepal. Journal of Clinical and Diagnostic Research, 5(8): 1585-1588.

37. Rezae, P., Safari, A.M., Montazerghaem, H., Reza, H.M., Paknahad, A. and Alavi, $A$ (2013): Comparing two training methods, traditional CPR skill and distance training at the Red Crescent organization in Hormozgan province. Life Science Journal, 10(9s): 140-145.

38. Rivers and Joynelle, L. (2012): Traditional vs. simulated guided methodology in teaching vital sign assessment of the normal newborn to the nursing student: A Clinical Outcome Evaluation, University of South Carolina: 108.

39. Salah,R.S. (2013): The effect of using simulation based learning versus traditional learning on nursing students' clinical performance of respiratory system. Thesis of doctorate, nursing science in nursing education, faculty of nursing, Alexandria University: 80
40. Shoemaker, M.J., Riemersma, L. and Perkins, R. (2015): Use of high fidelity human simulation to teach physical therapist decision-making skills for the intensive care setting. cardiopulm Phys Ther J, PMCID; 20(1): 13-18.?

41. Simonsen B.O. Daehlin G.K. Johansson I. Farup P.G. (2014): Differences in medication knowledge and risk of errors between graduating nursing students and working registered nurses: Comparative study. BMC Health Services Research, 14, 580. 10.1186/s12913-014-0580-7

42. Smeulers $M$, Onderwater AT, van Zwieten MC \& Vermeulen $H$ (2014) Nurses' experiences and perspectives on medication safety practices: an explorative qualitative study. Journal of Nursing Management 22, 276-285.

43. Swamy, M., Bloomfield, T.C., Thoma, R.H., Harnaik, S. and Roger, F. (2013): Role of SimMan in teaching clinical skills to preclinical medical students. BMC Medical Education, 13(20): 133.

44. Volpe CRG, Pinho DLM, Lima MMS, Santos WS, Rehen TCSB, et al. (2017): Mapping the Medication System: Weaknesses and Risk Management. J Nurs Care 6:395. doi:10.4172/21671168.1000395

45. Waxman, K. T. and Telles, C. L. (2010): The use of Benner's framework in highfidelity simulation faculty development the bay area simulation collaborative model. Clinical Simulation in Nursing, 5: 231235. 